\title{
POLICING, DRUGS, AND THE HOMICIDE DECLINE IN NEW YORK CITY IN THE 1990s*
}

\section{STEVEN F. MESSNER}

Department of Sociology

University at Albany, State University of New York

\section{SANDRO GALEA}

Department of Epidemiology

University of Michigan School of Public Health

\section{KENNETH J. TARDIFF}

Department of Psychiatry

Weill School of Medicine

Cornell University

\section{MELISSA TRACY}

Department of Epidemiology

University of Michigan School of Public Health

\section{ANGELA BUCCIARELLI \\ TINKA MARKHAM PIPER}

VICTORIA FRYE

DAVID VLAHOV

Center for Urban Epidemiologic Studies

New York Academy of Medicine

KEYWORDS: firearms, cocaine, broken windows, urban, violence

This research reassesses the role of policing and drugs in the sharp homicide decline in New York City in the 1990s. Drawing on theoretical arguments about "broken windows" policing and lethal violence

* This research has been supported in part through grants DA 06534 and DA 017642 from the National Institute on Drug Abuse (NIDA). We are grateful to Bernard Harcourt, Jens Ludwig, Lawrence Raffalovich, and the anonymous referees for comments on earlier drafts of this article. Address correspondence to Steven F. Messner, 1400 Washington Avenue, Arts and Sciences 351, University at Albany, Albany, NY 12222 (e-mail: s.messner@albany.edu). 
associated with the diffusion of crack cocaine, we estimate the effects of measures of misdemeanor arrests and cocaine prevalence on homicide rates with pooled, cross-sectional time-series data for 74 New York City precincts over the 1990-1999 period. The results of mixed regression models reveal a significant negative effect of changes in misdemeanor arrests and a significant positive effect of changes in cocaine prevalence on changes in total homicide rates. Additional analyses of homicide disaggregated by weapon indicate that the effects of misdemeanor arrests and cocaine prevalence emerge for gun-related but not for nongun-related homicides. Overall, the research generally supports influential interpretations of the homicide decline in New York City but also raises questions about underlying mechanisms that warrant more inquiry in future research.

The decline in homicide levels in New York City over the course of the 1990s has been the source of intense scrutiny in the popular press and in the scholarly literature. The basic facts are well known. Levels of homicide fell abruptly and precipitously over a relatively short period of time. In 1990, 2,245 criminal homicides were recorded. This figure dropped to 633 in 1998, which is a decrease of 72 percent (Karmen, 2000: 24). Although other major cities also exhibited falling homicide rates during the 1990s, special attention has been directed toward the New York City experience, caused in part by the city's preeminent status as the "media capital of the United States" (Fagan, Zimring, and Kim, 1998: 1277). As Karmen (2000: 29) observes, "word travels fast about cutting-edge developments and emerging trends in the 'backyard' of major media outlets."

Although little disagreement exists about the impressive scope of the homicide decline in New York City during the 1990s, the reasons for this phenomenon are the subject of vigorous debate. The popular media and public officials have assigned much credit to policing strategies implemented by William Bratton while serving as the head of the New York Police Department (Bratton, 1998; Conklin, 2003; Kelling and Bratton, 1998). Bratton's innovations encompassed a range of policies that have been loosely characterized under rubrics such as "zero tolerance policing," "quality-of-life policing," "broken windows policing," and "order maintenance policing" (Eck and Maguire, 2000; Kelling and Coles, 1996). In an "insider's" assessment of the contribution of this kind of policing to the homicide decline in New York City, Kelling and Bratton (1998: 1227) observe that "no credible alternatives ... have been put forth to contradict our belief that police action played a pivotal role."

The criminological community, however, has generally responded to such claims about the prominent role of policing as an explanation for the 


\begin{tabular}{lllll}
\hline ||server05\productn\C|CRY\45-2\CRY205.txt & unknown & Seq: 3 & 14-MAY-07 & 17:13 \\
\hline
\end{tabular}

declining homicide levels in New York City, in particular, and in the nation, in general, with a good deal of skepticism. Critics have cautioned that, although policing might have played some role in the homicide drop, other factors are likely to be as important or more important (Bowling, 1999; Eck and Maguire, 2000; Joanes, 2000; Levitt, 2004; National Research Council, 2004). One of the most highly touted alternatives to the policing explanation involves changes in crack cocaine markets (Blumstein and Rosenfeld, 1998; Blumstein, Rivara, and Rosenfeld, 2000; Rosenfeld, 2002). Proponents of this position point to a temporal overlap between homicide trends and the spread of crack cocaine. Homicides began to increase around the time that crack-cocaine markets emerged and started to decline when crack markets began to shrink.

These two explanations are not, of course, mutually exclusive. Both policing and changes in drug-related activities may have contributed to the drop in homicides in New York City. Yet despite extensive speculation, actually very little direct evidence exists on the relative impact of policing and drugs. Two of the most rigorous studies to date are those of Kelling and Sousa (2001) and Harcourt and Ludwig (2006). ${ }^{1}$ On the basis of a pooled, cross-sectional time-series design with police precincts serving as units of analysis, Kelling and Sousa find that the number of misdemeanor arrests is significantly related to a composite measure of violent crime (murder, rape, robbery, and felonious assault), which is consistent with the thesis of "broken windows" policing. They detect no evidence for a role of decreasing use of cocaine. In contrast, in a reanalysis of these data, Harcourt and Ludwig report that the effect of misdemeanor arrests on violent crime falls below statistical significance when the regression model is expanded to include a more comprehensive array of controls. The measure of cocaine use is not significant in the Harcourt and Ludwig models, which is similar to the earlier findings.

In this article, we build on and extend the prior work by Kelling and Sousa and Harcourt and Ludwig in several respects. First, in addition to examining the impact of policing and cocaine on total levels of homicide, we disaggregate homicides into categories of gun-related and non-gun-

1. Rosenfeld, Fernango, and Baumer (2005) have conducted a highly sophisticated analysis of the impact of policing on the homicide decline in three cities: Boston, New York, and Richmond, VA. They apply growth curve analysis and report that the New York City homicide trend did not deviate significantly from other large cities in the 1990s, which raises questions about the role of the Bratton policing strategies. The authors acknowledge that their data do not allow for an evaluation of the "three interventions per se" (2005: 422), and they characterize their work as "a point of departure for ongoing evaluation of the impact of local law enforcement interventions on crime rates" (2005: 440). 
related. This procedure is very useful because past research has demonstrated that these two forms of homicide exhibit distinct trends in New York City over the period under examination (Fagan, Zimring, and Kim, 1998). Moreover, theoretical reasons exist to expect that the effects of both policing and drug markets are likely to have been particularly pronounced for gun homicides (Fagan, Zimring, and Kim, 1998: 1319-20; Karmen, 2000: 117). Second, whereas the indicator of drug activity in the Kelling and Sousa research is a rough proxy measure based on hospital discharge data for the boroughs in New York City, we employ a more refined indicator, measured at the appropriate precinct level. Third, we introduce into the analyses a measure of felony arrests. This measure enables us to examine the extent to which any apparent effect of more vigorous enforcement of relatively minor crimes in particular is confounded with more vigorous policing in general. Our analyses thus provide a more thorough assessment than previously conducted of the role of the two major suspects in the "New York Murder Mystery" (Karmen, 2000).

\section{THE RESEARCH CONTEXT}

Kelling and Sousa (2001: 1-3) locate their study within the context of a more general debate about the relevance of policing for crime prevention. They call attention to the "long-prevailing" view enunciated by Sir Robert Peel, founder of London's Metropolitan Police, that the primary mission of the police is to prevent crime and disorder. This view, Kelling and Sousa maintain, was widely accepted until the 1950s. Around this time, basic questions were raised about what the police actually do, and the resulting research challenged the conventional wisdom about the impact of the police on crime. These findings fostered a general orientation toward crime that emphasizes "collective 'root causes' like social injustice, racism, and poverty" (2001: 3). The "root causes" orientation toward crime causation, in turn, is conducive to a highly skeptical stance about policing, i.e., the view that the police really do not matter when it comes to preventing crime.

Although the skeptical appraisal of the role of the police tended to dominate discourse during the 1970s and 1980s, Kelling and Sousa identify dissenting voices. These voices include the Goldstein (1979) arguments about "problem-oriented policing." According to this perspective, incidents coming to the attention of the police are best regarded as manifestations of underlying problems, and the proper role of the police is to address these problems. A second idea that has become particularly influential is that of "broken windows" policing, which was originally popularized through the Atlantic Monthly article by Wilson and Kelling (1982). The underlying premise of this approach is that disorder and incivility frighten residents and 
\begin{tabular}{lllll}
\hline ||server05\productn\C|CRY\45-2\CRY205.txt & unknown & Seq: 5 & 14-MAY-07 & 17:13 \\
\hline
\end{tabular}

POLICING, DRUGS \& THE HOMICIDE DECLINE

lead them to withdraw, thereby weakening informal social control and emboldening offenders. ${ }^{2}$ The police can, accordingly, reduce levels of serious crimes by enforcing minor violations, such as disorderly conduct and prostitution (fixing broken windows), and maintaining order.

Police officials in New York City embarked on a deliberate effort to put "broken windows" theory into practice (Kelling and Bratton, 1998). Kelling initially worked with New York City transportation authorities to develop proactive policing in the subways and then with Bratton to implement such policies more generally in the city after Bratton became the head of the New York City Police Department (NYPD) (Kelling and Sousa, 2001: 2). The policing reforms under Bratton's leadership encompassed an array of specific tactics (Conklin, 2003: 31-5; Karmen, 2000: 83-140). Bratton emphasized the importance of accurate and current statistics to inform decision making, and he promoted the use of computerized data and maps of "hot spots," which is a method often referred to as "Compstat." He also introduced corporate-style management techniques, which gave precinct commanders more authority but also held them accountable for improvements (or the lack thereof) in their precincts (Conklin, 2003: 39). The policing reforms in New York City were thus multifaceted, but the "lynchpin strategy," according to Bratton himself, was the "strict enforcement of laws against quality-of-life offenses such as subway turnstile jumping, aggressive panhandling, drinking and being drunk in public, and soliciting prostitutes" (Conklin, 2003: 37). Precinct commanders evidently heeded the Bratton directives; more than twice as many non-felony arrests were made in 1998 as in 1989, whereas the number of felony arrests actually decreased over this period (Solomon, 2003).

The dramatic decline in homicide in New York City during the 1990s thus coincided with a deliberate policy intervention. However, criminologists have called for caution in attributing the homicide drop in New York City primarily to innovations in policing, citing various alternative interpretations. One of the more highly regarded alternatives emphasizes the critical role of drug markets, in particular crack-cocaine markets, as a major source of lethal violence in large cities (Bowling, 1999).

The "crack-cocaine" thesis was originally introduced by Blumstein (1995) to account for the so-called homicide epidemic in urban America during the 1980s and early 1990s. According to Blumstein (1995), the demand for crack cocaine emerged in select cities in the mid-1980s and spread thereafter to other parts of the nation. Within any given locale, the

2. The Wilson and Kelling arguments about "broken windows" can be viewed as a variant of a more general approach to policing that emphasizes the importance of maintaining order. Taylor (2001: ch. 3) provides an extended discussion of different variants of the "incivilities thesis" of policing. See also Skogan (1990). 
increased demand for crack led to the recruitment of young minority males to serve as drug dealers. Violence typically surrounds drug markets (Goldstein, 1985), and thus, these new recruits acquired firearms for protection. The increased gun toting of those involved in crack-cocaine trafficking then diffused throughout the community at large, especially to other youths, as those not involved in the drug trade took up arms for selfdefense. As guns spread through the general population, interpersonal disputes became more lethal, which resulted in a rising homicide rate. Subsequently, the number of crack users dropped off, beginning in some cities in the early 1990s (Golub and Johnson, 1997). This decrease in the demand for crack alleviated the pressures for the recruitment of more drug dealers and brought some stability to drug markets. As the crack epidemic began to subside, homicide rates started to fall.

Several types of evidence lend credibility to the drug market/arms race explanation for homicide trends over recent decades. The argument is consistent with the documented demographics of homicide (Blumstein and Rosenfeld, 1998; Cook and Laub, 2002; Rosenfeld, 2002). The epidemiclike pattern of rapid increase followed by sharp reversal and decline was most pronounced among young African-American males, which is precisely the population that is hypothesized to have been recruited into, and subsequently out of, crack-cocaine markets. In addition, the growth in homicides among young people during the late 1980s was driven largely by the increase in homicides committed with handguns. ${ }^{3}$ This finding is consistent with the claims about the accelerating arms race spawned by the acquisition of guns by newly recruited drug dealers. Furthermore, the evidence indicates that the "timing" of the increases and declines in homicide across cities is consistent with the drug-market thesis. The larger, denser cities along the coasts - those most susceptible to the spread of cocainetended to be in the "vanguard" in the homicide epidemic (Messner et al., 2005). Research also suggests that measures of illegal drug activity can explain changes in homicide rates across metropolitan areas in the United States (Ousey and Lee, 2002). Finally, an attractive feature of the drug market/arms race thesis of changing homicide levels is its symmetrical quality. It accounts for both the rise and the fall of homicide levels in a logically consistent fashion (Blumstein and Rosenfeld, 1998: 1209). ${ }^{4}$

3. Wintemute (2000: 53) observes that recent trends in overall homicides (not merely youth homicides) "were driven almost entirely by trends in handgun homicide."

4. Focusing specifically on youth violence, Cook and Laub (2002: 145) question whether the "downside" of the homicide epidemic is, in fact, a mirror image of the "upside," specifically with respect to the sex, race, and ethnicity of offenders and to weapon use. 


\begin{tabular}{lllll}
\hline ||server05\productn\C|CRY\45-2\CRY205.txt & unknown & Seq: 7 & 14-MAY-07 & 17:13 \\
\hline
\end{tabular}

In sum, the impressive decline in homicides in New York City that coincided with concerted efforts to implement "broken windows" theory has positioned the general question of the impact of policing on crime prevention at the forefront of criminological discourse. The resulting debates have been vigorous, even "rancorous" (Eck and Maguire, 2000: 225). Moreover, as Eck and Maguire observe, the New York City experience is particularly important because the specific strategies of Bratton have been offered as a "blueprint" for reducing crime that should be applicable anywhere, and because police agencies throughout the world have, in fact, implemented similar strategies based on the New York City experience (2000: 228). Assessing the actual impact of "broken windows" policing on the homicide decline in New York City, in comparison with the effects of credible alternative factors, in particular with drugs, is thus a topic of high priority for criminological inquiry.

\section{PRIOR ASSESSMENTS}

Kelling and Sousa (2001: 3) confront this challenge by introducing a design that, in their view, allows for the "most definitive assessment of whether police tactics-particularly 'broken-windows' policing-explain recent crime trends in New York City." The key feature of the Kelling and Sousa research design is the pooling of cross-sectional and longitudinal data for New York City police precincts. In essence, rather than treating New York City as a single city, they view it as 75 different cities corresponding to the respective police precincts (2001: 4). The precincts vary with respect to police activity, drug markets, and social structural characteristics, and they exhibit differing trends in violent crime over the period under investigation: 1989-1998. With the pooled, cross-sectional, timeseries data, the relationships among the variables of interest within New York City can be examined while effectively controlling for factors that affected the city at large.

The dependent variable in the Kelling and Sousa multivariate analysis is a composite measure of complaints at the precinct level for four violent offenses: murder, rape, robbery, and felonious assault. The key independent variable is precinct-level arrests for misdemeanors, which serves as the indicator of "broken windows" policing. 5 Three additional measures are included to represent variables that have been offered as possible

5. In a study based on data for the early 1980s, Sampson and Cohen (1988) introduce a creative measure of "aggressive policing" - arrests for disorderly conduct and driving under the influence (DUI) per police officer. They report that this measure is negatively related to robbery rates for a sample of large cities, which is consistent with the deterrence perspective. A more recent study by MacDonald (2002) using a comparable measure reaffirms the earlier findings of Sampson and Cohen. 
alternatives to the policing explanation for the violent crime decline. To capture demographics, they include an indicator of "young males" (the number of males enrolled in public schools in each precinct). The two other measures reflect economic conditions (number of unemployed persons) and patterns of drug use (hospital discharges for cocaine-related incidents). Because of data limitations, unemployment and hospital discharges are measured at the borough rather than at the precinct level. The data on hospital discharges are available over time, whereas the measures of young males and unemployment are based on 1990 census data.

Kelling and Sousa use hierarchical linear modeling (HLM) to assess their hypothesis about the effects of "broken windows" policing. They treat time as a level 1 variable, and the independent variables as level 2 variables. Their results indicate that the time trends in violent crime complaints vary significantly across precincts. Moreover, when they examine the effects of the level 2 variables on the time slopes, they find that the measure of misdemeanor arrests yields the expected negative effect: Precincts with a high average number of misdemeanor arrests experienced a greater decline in violent crime. The coefficients for the measures of young males and borough cocaine fail to attain statistical significance, whereas the coefficient for borough unemployment is significant in the counterintuitive negative direction (higher unemployment, greater crime decline). Overall, Kelling and Sousa conclude that the results support their main hypotheses: “'[B]roken windows' policing is strongly associated with the decline in violent crime in precincts, while major competing explanations are not" (2001: 10).

Harcourt and Ludwig (2006) have recently challenged this conclusion. They identify a problematic feature of the Kelling and Sousa two-level, hierarchical growth model. This model "basically relates changes in violent crimes (each precinct's linear trend in violent crime over the 1989-98 period) against the levels of misdemeanor arrests (average arrests from 1989 to 1998)." In so doing, the analysis effectively "throws away all of the over-time variation in misdemeanor arrests across precincts from 1989 to 1998" (Harcourt and Ludwig, 2006: 293). This approach not only sacrifices useful information, but it also makes the analysis susceptible to a spurious relationship between policing and violent crime because the average level of misdemeanor arrests is strongly correlated with initial levels of violent crime. It is thus plausible to speculate that precincts that experienced an unusually high increase in violent crime during the "epidemic" period of the 1980s would yield the greatest decrease in the 1990s as a result of a simple reversion to the mean.

Harcourt and Ludwig challenge the Kelling and Sousa conclusions with several empirical illustrations. Harcourt and Ludwig use similar data to that used by Kelling and Sousa to measure violent crime, misdemeanor 


\begin{tabular}{lllll}
\hline ||server05\productn\C|CRY\45-2\CRY205.txt & unknown & Seq: 9 & 14-MAY-07 & 17:13 \\
\hline
\end{tabular}

arrests, and the control variables. In addition, Harcourt and Ludwig incorporate measures for a wide range of sociodemographic characteristics recorded at the census tract level, which are then aggregated to the precinct level. They also include a measure of the number of police officers assigned to each precinct to account for increases in manpower during the period, a measure of the level of violent crime at the beginning of the period, and a measure of change in violent crime for earlier years (1984-1989).

Harcourt and Ludwig first replicate the key coefficients reported by Kelling and Sousa using the HLM statistical framework. They then estimate a series of models that follows "the same intuition" of the Kelling and Sousa approach (Harcourt and Ludwig, 2006: 294). However, instead of modeling the linear time trend in violent crimes, they follow more conventional practices and model their dependent variable as the actual change in violent crime over the 1989-1998 period for each precinct. 6 They find that the average number of misdemeanor arrests exhibits a significant negative relationship with changes in violent crime, which is consistent with Kelling and Sousa. The introduction of the measure of violent crime at the beginning of the period, as well as the measure of changes in violent crime in the years preceding the period, reduces the magnitude of the policing variable, although it remains statistically significant in a negative direction. However, after the full complement of control variables is entered, the effect of misdemeanor arrests falls below statistical significance. Harcourt and Ludwig also estimate a first-difference model wherein changes in violent crime are related to changes in misdemeanor arrests, along with controls. The results of these analyses offer no support for the broken windows thesis. Overall, Harcourt and Ludwig conclude that their reanalysis of the New York City data leads them to a Scotch verdict: "not proven" (2006: 276). ${ }^{7}$

6. Harcourt and Ludwig (2006: 294) question the modeling of the linear time trend, given the nonlinearity in the time series for violent crime.

7. After their reanalysis of the New York City precinct-level data, Harcourt and Ludwig critically evaluate research by Corman and Mocan (2002). Corman and Mocan analyze monthly, time-series data for New York City at large and find support for the broken windows thesis for robbery and motor vehicle theft (but not for murder). Harcourt and Ludwig illustrate the limitations of research designs that rely on a single jurisdiction and show how the New York City data are consistent with alternative interpretations. Harcourt and Ludwig also report evidence from the Moving to Opportunity (MTO) experiment to assess whether movement to less-disadvantaged, less-disorderly neighborhoods is associated with reduced criminal behavior. They find that, in general, relocation to less disorderly communities does not reduce offending, which they regard as strong evidence contrary to the "broken windows" thesis. 


\section{THE CURRENT STUDY}

We adopt the same basic research design of these previous assessments of the impact of changes in policing in New York City-a pooled, crosssectional, time-series design - but reorient and extend the analysis in several ways. We focus primary attention on the offense of homicide. Criminologists generally agree that the official data on homicide are superior to those for other offenses because homicides are likely to be reported and recorded. O'Brien (1996) demonstrates, for example, that the apparent increase in national rates of nonlethal violent crimes (rape, robbery, and aggravated assault) in the Uniform Crime Reports over the 1973-1992 period can be plausibly attributed to increases in police productivity rather than to increases in violent incidents. This type of measurement error is particularly consequential in any effort to assess the impact of "broken windows" policing. Such policing is likely to be associated with increased pressures for recording, which would operate in the opposite direction of any genuine crime-reducing effect.

In addition, our homicide data allow us to distinguish between gunrelated and non-gun-related offenses. Fagan, Zimring, and Kim (1998: 1319) have examined homicide trends in New York City from the mid1980s through the 1990s and have concluded that "two separate types of homicides with two discrete time trends" exist: gun and non-gun homicides. Non-gun homicides begin their decline before the widely publicized policing changes and exhibit a fairly steady decline. Such a trend does not suggest that innovations during the Bratton regime had substantial impact. In contrast, "the temporal fit between policing changes and gun homicide declines is a good one" (Fagan, Zimring, and Kim, 1998: 1319). ${ }^{8}$ Moreover, as Fagan, Zimring, and Kim note (1998: 1322), the order maintenance techniques implemented in NYC “. . . can have gun-specific results if police use them to produce gun search opportunities." The more vigorous enforcement of minor infractions might accordingly contribute to a decline in homicides by deterring casual gun toting, which is an effect that would be expected for gun-related, but not necessarily non-gun-related, incidents (Karmen, 2000: 117). Broken windows policing would thus seem to be a more plausible candidate for the explanation of gun-related than non-gunrelated homicides on both empirical and theoretical grounds.

We also improve on the measurement of a key variable considered in previous research: drug use patterns, in particular, cocaine use. The prior

8. Fagan, Zimring, and Kim (1998: 1320) caution that it is extremely difficult to "parse causal responsibility" for policing and other factors. They speculate that "the pattern of policing in New York City is more consistent with gun-oriented policing than with indiscriminate quality-of-life interventions as a cause of decline" (1998: 1322; see also Fagan and Davies, 2003). 


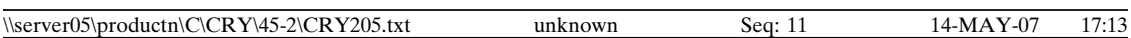

\section{POLICING, DRUGS \& THE HOMICIDE DECLINE 395}

assessments of broken windows policing in New York City have used hospital discharge data, which are available at the borough level, whereas violent crime has been measured at the lower, precinct level of aggregation. As Harcourt and Ludwig (2006: 317) observe, the resulting measurement error is likely to attenuate the relationship and bias the coefficient toward zero. It is thus plausible to speculate that the importance of cocaine use has been underestimated in prior analyses based on drug data for New York City boroughs. We rely on a different data source: medical examiner records of cocaine levels among persons who were accident decedents. This data source has two highly desirable features. Through geocoding, addresses can be determined and a measure of drug use can be constructed that refers to the appropriate precinct (rather than borough) level. In addition, accident victims are likely to mimic persons in the general population, whereas hospital discharge data might under-represent cocaine use among the public at large (see Galea et al., 2003).

Our analysis also extends prior work by introducing an alternative indicator of policing: felony arrest rates. Precincts with increasing misdemeanor arrests might be characterized by more intensive enforcement activity of the police in general, and any apparent effect of "broken windows" policing might actually be spurious. Homicide declines might be most prominent in those precincts where police activity of all kinds intensified. This result would be more consistent with a general deterrence interpretation than an interpretation that credits crackdowns on qualityof-life offenses.

Finally, we estimate models for another violent offense, robbery rates, to determine the robustness of the results, and we build on the earlier work by explicitly considering multivariate models that take into account potentially confounding sociodemographic covariates that are well established in the homicide literature (Land, McCall, and Cohen, 1990) as well as an indicator of police manpower changes that occurred during the period under investigation.

\section{DATA AND METHODS}

Data for this study were collected from three principal sources: the Office of the Chief Medical Examiner (OCME) of New York City, the NYPD, and the U.S. Census Bureau. All cases of homicides, suicide, and accident deaths in New York City from 1990 to 1999 were identified through standardized manual review and abstraction of medical files in the OCME of New York City. The OCME is responsible for investigating all deaths of people believed to have died from unnatural causes. Thus, all homicide, suicide, and accident deaths in New York City are reviewed by the OCME and would have been included in the charts used for data 
extraction. In addition, the Chief Medical Examiner has been the same person from 1990 to the current time in New York City, so the forms, classification of cases, toxicology, policies, and other aspects of the OCME have remained the same over the time period covered in this study.

Data regarding cause of death, circumstances of death (including use of a gun), and toxicology were collected from the OCME files by trained abstractors using a standardized protocol and data collection forms. The OCME investigators used the medical history of the decedent, the circumstances and environment of the death, autopsy findings, and laboratory data, to attribute the cause of death to each case reviewed. All OCME cases from 1990 to 1999 were then geocoded to the police precinct level by address of injury using ArcGIS software, version 9.0 (ESRI, Redlands, CA). Only cases with a valid address of injury were included in the analysis.

The units of analysis for the research are New York City police precincts. Police precincts are useful area-level units for the assessment of the broken windows thesis because law enforcement is organized at the precinct level (Fagan, West, and Holland, 2003: 1566). Precincts 33 and 34, covering the Washington Heights and Inwood areas, were treated as one precinct because they were split only in 1994. The Central Park precinct (Precinct 22) was excluded a priori because no one resides in this precinct, and thus, no population denominator is available for rate estimation.

\section{DEPENDENT VARIABLES}

Our dependent variables are total homicide rates, gun-related and nongun-related homicide rates, and robbery rates. Homicide deaths were collected from the OCME and robberies from the NYPD; rates were calculated per 100,000 population using data from the 1990 census as the relevant denominator.

\section{INDEPENDENT VARIABLES}

The two key independent variables (misdemeanor arrests and cocaine use) are both time-varying variables. The NYPD routinely collects data on all police arrests for various causes by precinct. Data were collected from the NYPD on all misdemeanor arrests by precinct from 1990 to 1999 to represent "broken windows"-oriented policing, which is consistent with prior research (Corman and Mocan, 2002; Harcourt and Ludwig, 2006; Kelling and Sousa, 2001). Misdemeanor arrest rates were also expressed as rates per 100,000 population using 1990 census population counts as the relevant denominator. The other key independent variable is level of cocaine use, measured as the proportion of accident decedents whose toxicology results were positive for cocaine in each precinct and recorded 


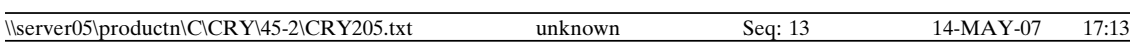

POLICING, DRUGS \& THE HOMICIDE DECLINE

from OCME data. ${ }^{9}$

\section{CONTROL VARIABLES}

We introduce controls for a wide range of sociodemographic characteristics of precincts that have been linked with homicide rates in past macrolevel research (Land, McCall, and Cohen, 1990). Data for these variables are available only for decennial years, and thus, they are measured as time invariant fixed at the 1990 census year. The specific measures are as follows:

Percent male. Percent persons in a given precinct who were male.

Percent under age 35 . Percent persons in a given precinct under age 35 years.

Percent black. Percent persons in a given precinct who were black.

Percent female-headed households. Percent households in a given precinct with a self-reported female head of household.

Percent of population on public assistance. Percent persons in a given precinct receiving pubic assistance.

Percent under 200 percent poverty. Percent persons in a given precinct earning less money annually than the 200 percent poverty margin.

Percent persons with less than high-school education: Percent persons in a given precinct over the age of 25 years with less than a highschool education.

Percent unemployed: Percent persons in a given precinct over the age of 15 years who were unemployed.

The data source for these sociodemographic control variables is the U. S. Census Summary File 3 (SF3). Infoshare Online (2007) was used to provide census data at the tract level, which were aggregated to the police precinct level.

Because some socioeconomic variables (percent of persons with less than high-school education, percent of persons under 200 percent poverty, percent of female-headed households, and percent of persons on public assistance) are highly intercorrelated, we conducted principal component

9. Our measure of cocaine use implicitly assumes that the risk of accidental death does not vary systematically across precincts. To assess the extent to which the results might be sensitive to differentials in this risk, we included a measure of the overall accidental death rate (as a change score) in our regression models for homicide. The inclusion of this measure has minimal impact on the parameter estimates for other covariates. The accidental death rate is significantly related to total, gun-related, and non-gun-related homicides: Increases in accidental deaths are associated with increases in homicides. 
analysis to construct an aggregate socioeconomic status score for each precinct, which is consistent with conventional practices in macrolevel homicide research (Land, McCall, and Cohen, 1990). The composite score was created by summing the four items, each weighted by its factor loading in the analysis. The composite index is scored in the direction of disadvantage: the greater the score, the poorer the socioeconomic status (range, 23.4-189.0).

In addition to the indicators of sociodemographic characteristics of precincts, we include controls for two other variables: a proxy for firearm availability and a measure of manpower levels. Researchers on firearms generally agree that, in the absence of accurate administrative data or representative survey data, the most reliable proxy measure for firearm availability is the percentage of suicides committed with a gun (Azrael, Cook, and Miller, 2004; Cook and Ludwig, 2006; Kleck, 2004).10 Our measure of firearm availability is the proportion of suicide deaths where guns were used per precinct per year. The indicator of manpower is the number of police officers assigned to each precinct in each year by the NYPD. ${ }^{11}$ Data on the firearm proxy and police manpower are available on an annual basis, and thus, these variables are expressed as annual change scores.

Finally, we also include a measure of felony arrests, collected from the NYPD by precinct from 1990 to 1999. Felony arrest rates are computed as rates per 100,000 population using 1990 census population counts as the relevant denominator and are entered into regression models as annual change scores. We include this variable to assess whether increased police activity at all levels or broken windows policing specifically contributed to the decline in homicides.

Of the 14,151 homicides that occurred in New York City from 1990 to 1999 , we were able to successfully geocode 12,971 cases to the police precinct level (91.7 percent of original sample). No systematic differences were found between homicide cases included in the analysis and cases excluded from the analysis. Univariate statistics for the variables in the analysis are reported in appendix A.

\section{ANALYTIC FRAMEWORK}

All analyses are based on "change" mixed models where we calculated year-to-year change for the key dependent and independent variables by

10. Kleck (2004) reports that the suicide proxy measure is valid for cross-sectional research but advises against using any standard proxies for longitudinal analyses. In contrast, Azrael, Cook, and Miller (2004) and Cook and Ludwig (2006) conclude that the percentage of suicides involving guns is a useful proxy for both kinds of analyses.

11. We are grateful to Bernard Harcourt and Jens Ludwig for providing the data on police manpower in a personal communication. 


\begin{tabular}{|c|c|c|c|}
\hline|| server05\productn $\backslash \mathrm{C} \backslash \mathrm{CR} Y \backslash 45-2 \backslash \mathrm{CRY} 205 . \mathrm{txt}$ & unknown & Seq: 15 & 14-MAY-07 \\
\hline
\end{tabular}

subtracting the relevant value at year $t$ from the value for the subsequent year $t+1$. Therefore, all models are of the following form:

$\Delta Y_{i j}=\alpha_{i}+\beta \Delta X_{i j}+\gamma X_{i}^{\prime}+e_{i j}+r \times e_{i j-1}$

where $\Delta Y_{i j}$ is the change in the dependent variable between times $t$ and $t+$ 1 for the $i$ th precinct in the $j$ th time interval, $\Delta X_{i j}$ is a vector of the change in the independent variables of interest for the $i$ th precinct in the $j$ th time interval, $X_{i}^{\prime}$ is the vector of time invariant baseline demographic characteristics measured in 1990, and $r$ is the autocorrelation coefficient. We use random intercept models to account for potential differences in baseline relations between key independent and dependent variables and account for intra-precinct correlation using an autoregressive correlation structure.

Our first set of analyses examines total homicides. We begin with an examination of the effect of changes in the misdemeanor arrest rate alone on changes in total homicide rates. Next, we estimate a model with predictor variables analogous to that examined by Kelling and Sousa. This model includes the indicator of cocaine use and the controls for age/sex structure and unemployment. We then introduce the additional control variables into the models. In additional analyses, we disaggregate homicides into gun-related and non-gun-related categories. We only report estimates for the full model for the disaggregated analyses. Finally, we expand the model to include the measure of felony arrests, and we estimate the effects of the full complement of predictor variables on total and disaggregated homicides and on robbery rates.

\section{RESULTS}

Initial results for total homicide rates are given in table 1 . Model 1 shows the bivariate effect of changes in the misdemeanor arrest rate on changes in the homicide rate. Consistent with the Kelling and Sousa findings and the thesis of broken windows policing, the coefficient is negative and statistically significant $(\beta=-.0013, p<.001)$. As the misdemeanor arrest rate in a precinct increases, the homicide rate decreases.

In model 2, control variables similar to those considered by Kelling and Sousa are introduced. The effect for the measure of changes in the misdemeanor arrest rate is unchanged within rounding, and it remains significantly negative. The measures of age/sex structure fail to attain a level of statistical significance, whereas the coefficient for unemployment is significant but in the unexpected negative direction. These findings are all similar to those reported by Kelling and Sousa. However, in contrast with this earlier research, our indicator of cocaine use, measured at the appropriate precinct level rather than at the borough level, is positive and statistically significant: As the proportion of accident victims with positive cocaine toxicology decreases, the homicide rate declines as well. 


\section{Table 1. Random Effects Models Predicting Change in Homicide Rates for NYC Police Precincts, 1990-1999a}

\begin{tabular}{lccc}
\hline & Model 1 & Model 2 & Model 3 \\
\hline Change in misdemeanor arrest rate & $-.0013^{* * *}$ & $-.0013^{* * *}$ & $-.0012^{* *}$ \\
Change in cocaine use ${ }^{\mathrm{b}}$ & & $.0761^{*}$ & $.0760^{*}$ \\
Percent male & & -.0148 & -.0268 \\
Percent under age 35 years & -.1046 & -.0448 \\
Percent unemployed & $-1.1755^{*}$ & -.8458 \\
Change in firearm availability $^{\mathrm{c}}$ & & -.0047 \\
Percent black & & .0052 \\
SES composite $^{\mathrm{d}}$ & & -.0233 \\
Change in manpower $^{\mathrm{e}}$ & & .0030 \\
\hline
\end{tabular}

ABBREVIATION: SES = socioeconomic status.

$* p<.05 ; * * p<.01 ; * * * p<.001$. $N=666$ precinct-years.

a 1990 U.S. Census precinct population used to calculate rates.

${ }^{\mathrm{b}}$ Annual change in proportion of accident decedents with positive cocaine toxicology.

${ }^{c}$ Annual change in proportion of suicides where guns were used.

${ }^{\mathrm{d}}$ SES composite index includes the following socioeconomic variables aggregated to the police precinct level: percent less than high-school education, percent less than 200 percent poverty, percent female-headed households, and percent receiving public assistance.

${ }^{\mathrm{e}}$ Annual change in size of police force in precinct.

The additional control variables are entered in model 3. The effect for changes in misdemeanor arrests withstands these additional controls. The regression parameter suggests that an increase of 833 misdemeanor arrests for a police precinct of 100,000 population would be associated with about one less homicide in that precinct. To further illustrate the magnitude of the effect of the misdemeanor arrest variable, we estimated predicted values for the change in homicide rates at varying percentiles of changes in misdemeanor arrests with the other covariates fixed at their mean values. The results are displayed in figure 1 . For precincts in the 25 th percentile of change in misdemeanor arrests, the predicted change in homicide rates is a drop of 2.51. The predicted fall in the homicide rate increases by about 1 for precincts in the 75th percentile (-3.47). The contrasts are striking at the extremes. For precincts in the 10th percentile of change in misdemeanor arrest rates, the predicted change in homicide rates is a decrease of 1.7 per 100,000 . For precincts in the 90th percentile of change in misdemeanor arrest rates, the predicted decrease in homicide rate is 4.2 per 100,000 . In other words, our statistical model suggests that the decrease in homicide was 2.5 times greater for precincts in the 90th percentile compared with those in the 10th percentile of change in misdemeanor arrest rate. 


\section{Figure 1. Change in Homicide Rates Associated with} Different Changes in Misdemeanor Arrest Rates by Precinct Percentile of Change in Misdemeanor Arrest Rates

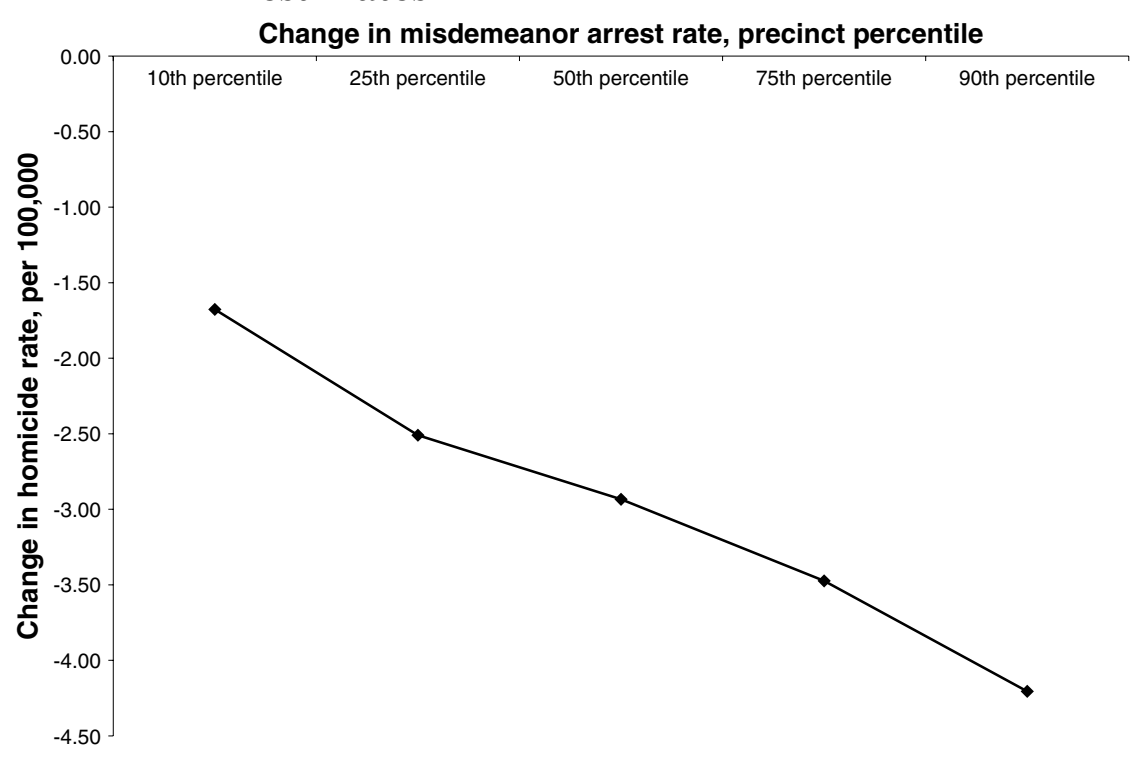

The findings in model 3 also reveal that the measure of cocaine use retains its significant, positive effect. 12 The regression parameters suggest that a 13 percent increase in cocaine use, as reflected by the proxy measure, would be associated with about one more homicide per precinct. The coefficients for the remaining predictor variables, in contrast, are not significant. The null effects for the sociodemographic characteristics might seem to be surprising, but recall that our "mixed" statistical models predict annual changes in homicide rates using time-varying indictors of misdemeanor arrests and cocaine arrests (as well as the firearm proxy and manpower measure), along with the time-invariant measures of sociodemographic characteristics. The sociodemographic characteristics, thus, can only explain cross-sectional variation and not variation over time within precincts. In a cross-sectional analysis with average values used in

12. To consider the possibility of mean reversion, we also estimated models that include two indicators of the growth in homicide in the years immediately preceding the time period under investigation: the simple difference in the homicide count between 1989 and 1984 and this difference as a proportion of the 1984 value. The effects of changes in misdemeanor arrests and cocaine use are unaffected by these additional controls. Bernard Harcourt and Jens Ludwig generously supplied the data for the measures of homicide before the 1990s. 


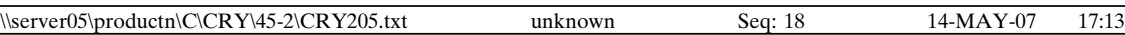

place of the time-varying measures (not shown but available on request), the expected impact of socioeconomic conditions on levels of homicide is observed. The indicator of socioeconomic disadvantage emerges as a strong and significant predictor of homicide rates: The more disadvantaged precincts exhibit significantly higher average levels of homicide.

Table 2 presents the fully specified model from table 1, which now predicts gun-related and non-gun-related homicides separately. The results reveal an important specification of the impact of changes in misdemeanor arrests and changes in drug use. Both measures exert significant effects on gun-related homicides but not on non-gun-related homicides. The pattern for misdemeanor arrests is consistent with the Fagan, Zimring, and Kim (1998: 1319) observation that the timing of policing changes in New York City "fits" gun homicide declines but not trends in non-gunrelated homicides. Similarly, the restricted impact of cocaine use on gunrelated homicide is consistent with key elements of the Blumstein crackcocaine thesis. The expansion and contraction of crack markets allegedly affected homicide rates through an associated arms race, which implies that changing patterns of drug use should affect gun-related homicides but not necessarily non-gun-related homicides.

If guns played a prominent role in changes in homicide rates in New York City, why is the coefficient for the gun availability proxy nonsignificant in our models? One possibility is that the proxy is invalid, but previous research has provided reasonably strong validation of this measure (Azrael, Cook, and Miller, 2004; Cook and Ludwig, 2006; Kleck, 2004). Alternatively, the causal linkage between general gun availability and homicides may be indirect and not well reflected in the relationship between the proxy and changes in homicides. Cook and Ludwig (2006: 386) argue, for example, that the primary mechanism by which gun prevalence produces high homicide rates is "through the transfer of guns from 'legal' to 'illegal' owners, rather than through increased gun misuse by otherwise legal owners." Accordingly, the general measure of gun availability may be too blunt an instrument to capture the kind of access to firearms that is likely to be related to homicides.

In table 3, we consider the possibility that the apparent effect of misdemeanor arrests is actually spurious because of more intensive policing in general, as reflected in more vigorous enforcement of serious law infractions (i.e., felony arrests). Changes in misdemeanor arrests are, in fact, positively and significantly correlated with changes in felony arrests $(r=$ $.305)$, and if the measure of changes in felony arrests is substituted for the measure of changes in misdemeanor arrests in the regression models, the pattern of results is highly similar for the two policing measures (results 
Table 2. Random Effects Models Predicting Change in Gun-Related and Non-Gun-Related Homicide Rates for New York City Police Precincts, 1990-1999a

\begin{tabular}{lcc}
\hline & \multicolumn{2}{c}{ Type of Homicide } \\
\cline { 2 - 3 } & Gun-Related & Non-Gun-Related \\
\hline Change in misdemeanor arrest rate & $-.0010^{* * *}$ & -.0002 \\
Change in cocaine use ${ }^{\mathrm{b}}$ & $.0749^{* *}$ & .0012 \\
Percent male & -.1226 & .0958 \\
Percent under age 35 years & -.0225 & -.0223 \\
Percent unemployed & -.2709 & -.5749 \\
Change in firearm availability & .0137 & -.0184 \\
Percent black $_{\text {SES composite }}^{\mathrm{d}}$ & -.0154 & .0206 \\
Change in manpower $^{\mathrm{e}}$ & -.0185 & -.0049 \\
\hline
\end{tabular}

ABBREVIATION: SES = socioeconomic status.

$* p<.05 ; * * p<.01 ; * * * p<.001 . N=666$ precinct-years.

a 1990 U.S. Census precinct population used to calculate rates.

${ }^{b}$ Annual change in proportion of accident decedents with positive cocaine toxicology.

${ }^{c}$ Annual change in proportion of suicides where guns were used.

${ }^{\mathrm{d}} \mathrm{SES}$ composite index includes the following socioeconomic variables aggregated to the police precinct level: percent less than high-school education, percent less than 200 percent poverty, percent female-headed households, and percent receiving public assistance.

${ }^{\mathrm{e}}$ Annual change in size of police force in precinct.

not shown but available on request). However, when both policing measures are included in the same equation predicting homicides in the models in table 3, only the misdemeanor arrest measure is statistically significant in the expected negative direction for total and gun-related homicide but not for non-gun-related homicide.

The results in the final column of table 3 also allow us to conduct an assessment of the robustness of the results for homicide across another violent offense: robbery. Similar to the results for homicide, increases in misdemeanor arrests are significantly associated with decreases in robbery rates. Interestingly, the effect of changes in cocaine use is not significant for robbery. 13

13. As an additional assessment of the robustness of the findings, we have introduced an indicator of change in levels of incarceration to the models. The measure refers to the number of prison admissions by precinct of arrest per 100,000 population, which is expressed as a change score analogous to the measure of change in misdemeanor arrests. The measure of change in incarceration has no effect on crime rates in any models, and controlling for change in incarceration 
Table 3. Random Effects Models Predicting Changes in Total, Gun-Related, and Non-Gun-Related Homicide Rates and Robbery Rates for New York City Police Precincts, 1990-1999, ${ }^{a}$ With Change in Felony Arrests

\begin{tabular}{|c|c|c|c|c|}
\hline & \multicolumn{4}{|c|}{ Type of Offense } \\
\hline & $\begin{array}{c}\text { Total } \\
\text { Homicides }\end{array}$ & $\begin{array}{c}\text { Gun-Related } \\
\text { Homicides }\end{array}$ & $\begin{array}{l}\text { Non-Gun- } \\
\text { Related } \\
\text { Homicides }\end{array}$ & Robberies \\
\hline Change in misdemeanor arrest rate & $-.0011 * *$ & $-.0009 * *$ & -.0003 & $-.0375 * * *$ \\
\hline Change in felony arrest rate & -.0010 & -.0012 & .0002 & .0221 \\
\hline Change in cocaine use $\mathrm{e}^{\mathrm{b}}$ & $.0747 *$ & $.0733 * *$ & .0014 & .9924 \\
\hline Percent male & -.0379 & -.1354 & .0976 & $-19.5133 * *$ \\
\hline Percent under age 35 years & -.0296 & -.0050 & -.0247 & $6.0517 *$ \\
\hline Percent unemployed & -.9600 & -.4031 & -.5569 & $-121.3400 * * *$ \\
\hline Change in firearm availability ${ }^{\mathrm{c}}$ & -.0045 & .0139 & -.0185 & .2001 \\
\hline Percent black & .0063 & -.0142 & .0204 & .6100 \\
\hline SES composite ${ }^{\mathrm{d}}$ & -.0242 & -.0194 & -.0047 & 1.1976 \\
\hline Change in manpower ${ }^{\mathrm{e}}$ & .0053 & .0082 & -.0029 & -.0285 \\
\hline
\end{tabular}

ABBREVIATION: SES = socioeconomic status.

$* p<.05 ; * * p<.01 ; * * * p<.001 . N=666$ precinct-years.

a 1990 U.S. Census precinct population used to calculate rates.

${ }^{b}$ Annual change in proportion of accident decedents with positive cocaine toxicology.

${ }^{c}$ Annual change in proportion of suicides where guns were used.

d SES composite index includes the following socioeconomic variables aggregated to the police precinct level: percent less than high-school education, percent less than 200 percent poverty, percent female-headed households, and percent receiving public assistance.

e Annual change in size of police force in precinct.

\section{SUMMARY AND CONCLUSIONS}

This research has reexamined the two leading interpretations for the dramatic decline in homicide rates in New York City in the 1990s: the "broken windows policing" thesis and the "crack-cocaine/drug activity" thesis. We have gone beyond prior work by 1) examining gun-related and non-gun-related homicides separately, 2) using a superior measure of drug activity based on cocaine toxicology of accident decedents, and 3) including a measure of felony arrests to help distinguish the effects of increased policing of "quality-of-life" offenses from intensified policing more generally. Our analyses have been based on pooled, cross-sectional, time-series data for 74 New York City precincts over the 1990-1999 period, with all variables measured at the appropriate precinct level. The results of our

rates has minimal impact on the parameter estimates and does not alter statistical significance. The incarceration data are from the New York State Division of Criminal Justice Services and were kindly provided by Richard Rosenfeld. 


\begin{tabular}{|c|c|c|c|}
\hline $\mid \backslash$ server05\productn $\backslash C \backslash C R Y \backslash 45-2 \backslash C R Y 205 . t x t$ & unknown & Seq: 21 & 14-MAY-07 \\
\hline
\end{tabular}

\section{POLICING, DRUGS \& THE HOMICIDE DECLINE 405}

mixed-regression models offer qualified support for each of the two leading explanations of the homicide decline in New York City, but they also raise some important questions.

We find that changes in misdemeanor arrest rates are negatively related to changes in total homicide rates. This effect is statistically significant, and it persists in the models controlling for sociodemographic characteristics at the beginning of the time period, changing levels of police manpower, and for changes in felony arrests. These findings support the Kelling and Sousa general claim that the implementation of new policing policies played a nontrivial role in the homicide decline in New York City.

We also observe that, when homicides are disaggregated by weapon use, the effect of changes in policing is significant for gun-related, but not for non-gun-related, homicide. This observation may reflect patterns of gun use by circumstances. For the nation at large, during the time period under investigation, guns were more likely to be used in felony and gang-related incidents than in other kinds of homicides, such as homicides evolving out of arguments (Bureau of Justice Statistics, 2006). It seems likely that policing policies will have more of an impact on homicides associated with felonies and gang activities than on argument-related homicides. The observation of an effect of misdemeanor arrests on gun-related homicides, but not on non-gun-related homicides, is also consistent with arguments advanced by Fagan, Zimring, and Kim (1998: 1322) that the kinds of changes in policing associated with broken windows theory might be effective, at least in part, by "taking guns off the street." Enforcement tactics resulting in greater police/citizen contacts presumably increase opportunities to search for, and apprehend, illegal guns that might otherwise be used in gun-related homicides.

We also find a significant effect of changes in cocaine use on changes in homicide rates. Declining cocaine use, as indicated by the toxicology of accident victims, is associated with decreasing homicide levels. Similar to the results for misdemeanor arrests, the effect of the cocaine measure is specified by weapon use; it emerges for gun-related homicides but not for non-gun-related homicides. These results are in accord with theoretical arguments about the close connection between crack-cocaine markets and the illegal use of guns.

We recognize that some limitations are associated with our analysis. The indicator of drug activity does not discriminate between crack cocaine and other forms of cocaine, and it reflects the levels of use rather than the features of the drug market operations. It is possible, for example, that patterns of cocaine use do not "map" closely with patterns of drug buying and selling, which implies that cocaine deaths by place of injury might not reflect the level of drug market activity. The findings for this measure thus 
bear indirectly on some specific claims of the "crack-cocaine market" thesis of the homicide decline.

More generally, causal inference is inherently precarious in nonexperimental designs, and the possibility of omitted variables bias cannot be dismissed. One particularly important concern for current purposes is that some unmeasured features of policing are correlated with misdemeanor arrests. We have included controls for levels of police manpower and felony arrests, but the practice of intensive policing of disorderly behavior in New York City was implemented as part of a larger constellation of organizational change and a reorientation of the mission of the NYPD (National Research Council, 2004: 230). Accordingly, the coefficient for misdemeanor arrests might be capturing other aspects of policing that were selectively adopted across precincts along with the intensive policing of disorder. Research on the effectiveness of various forms of policing has revealed that the most successful innovations have been those that combine highly focused police efforts with "an expansion of the tool box of policing beyond simple law enforcement" (Weisburd and Eck, 2004: 42). It is thus plausible to speculate that the policing of disorder operated in concert with other police practices that have been shown to be effective in a wide range of contexts to reduce levels of homicide in New York City. Clarifying the precise mechanisms underlying the finding of a negative effect of misdemeanor arrests on homicides is an important challenge for future research.

In addition, data availability inhibits the assessment of the importance of changes in policing or drug activity on the homicide decline relative to improvements in the kinds of social conditions that have been linked with violent crime in the macro-criminological literature. Our models include a wide range of measures of sociodemographic characteristics as controls, but these measures are based on census data and are time invariant. We thus can take into account appreciable differences in the levels of sociodemographic characteristics across precincts at the beginning of the decade, but we cannot estimate the relationships between changes in theoretically relevant social conditions and changes in homicide. 14 Although we can only speculate, it seems likely that both law enforcement

14. Note also that our analyses are confined to relatively short-term effects of policing. Research by Fagan, West, and Holland (2003) suggests that incarceration has adverse consequences for the social ecology of neighborhoods that increase the likelihood of crime in the long run. As reported in footnote 13, an indicator of contemporaneous change in incarceration rates has no effect on change in homicide rates in our sample, but to the extent that proactive policing leads to increased incarceration, and incarceration stains "the social and psychological fabric of neighborhood life," as suggested by Fagan, West, and Holland (2003: 1589), the long-term effect of policing might be contrary to its short-term effect. 


\begin{tabular}{|c|c|c|c|}
\hline $\mid \backslash$ server05\productn $\backslash C \backslash C R Y \backslash 45-2 \backslash C R Y 205 . t x t$ & unknown & Seq: 23 & 14-MAY-07 \\
\hline
\end{tabular}

\section{POLICING, DRUGS \& THE HOMICIDE DECLINE}

and social trends are likely to have contributed to declining gun homicide in New York City (see Fagan, Zimring, and Kim, 1998: 1320).

Another issue that requires more consideration is the reason for the discrepancies between our findings and the previous results of Harcourt and Ludwig (2006). We employ a similar modeling strategy, regressing crime changes on arrest changes, yet arrive at divergent conclusions. One obvious difference between the two studies is the dependent variable. Homicide and robbery serve as the dependent variables in the analyses reported above, whereas Harcourt and Ludwig model a composite measure of violent crime based on the sum of criminal homicides, rapes, felonious assaults, and robberies. However, when we substitute a composite violent crime measure in our regression models, the results for misdemeanor arrests and the cocaine measure replicate those for homicide and robbery. The differences across studies for the cocaine measure are perhaps not surprising, given that our proxy is measured at the precinct rather than at the borough level, but the varying results for misdemeanor arrests are perplexing. We have included a range of control variables similar to those of Harcourt and Ludwig, but some differences in model specification exist. An important task for future research is to isolate those design features of the respective studies that can account for the divergent findings.

We close with a caution about the policy implications of our findings of significant negative effects of changes in misdemeanor arrests on changes in homicide rates. Local governmental officials confront difficult choices in the allocation of scarce resources, and thus, investments in policing policies must be weighed against alternative strategies for improving the quality of life in the city. Moreover, the potential dangers associated with policing disorder have long been recognized. These strategies grant the police considerable discretion, which under certain circumstances may be conducive to the excessive use of force, brutality, and prejudicial enforcement (Skogan, 1990: 164; see also Greene, 1999). Indeed, critics have suggested that the social costs associated with broken windows policing in New York City have exceeded any ostensible benefits (Karmen, 2000: 120). Thus, although our analyses suggest that innovations in policing hold promise for crime reduction, we echo earlier calls for careful cost/benefit calculations and a judicious balancing of the goals of crime control and social justice in deliberations about the implementation of forms of proactive policing (Sampson and Cohen, 1988: 186). 


\section{REFERENCES}

ArcGIS, version 9.0. 2004. ESRI, Redlands, CA.

Azrael, Deborah, Philip J. Cook, and Matthew Miller. 2004. State and local prevalence of firearms ownership: Measurement, structure, and trends. Journal of Quantitative Criminology 20:43-62.

Blumstein, Alfred. 1995. Youth violence, guns, and the illicit-drug industry. Journal of Criminal Law and Criminology 86:10-36.

Blumstein, Alfred, and Richard Rosenfeld. 1998. Explaining recent trends in U. S. homicide rates. Journal of Criminal Law and Criminology 88:1175-216.

Blumstein, Alfred, Frederick P. Rivara, and Richard Rosenfeld. 2000. The rise and decline of homicide. Annual Review of Public Health 21:505-41.

Bowling, Benjamin. 1999. The rise and fall of New York murder. British Journal of Criminology 39:531-54.

Bratton, William J., with Peter Knobler. 1998. Turnaround: How America's Top Cop Reversed the Crime Epidemic. New York: Random House.

Bureau of Justice Statistics. 2006. Homicide Trends in the U. S.: Homicide Circumstances. U.S. Department of Justice. http://www.ojp.usdoj.bjs/ homicide/circumst.htm.

Conklin, John E. 2003. Why Crime Rates Fell. Boston, MA: Allyn and Bacon.

Cook, Philip J., and John H. Laub. 2002. After the epidemic: Recent trends in youth violence in the United States. In Crime and Justice: A Review of Research, Vol. 29, ed. Michael Tonry. Chicago, IL: University of Chicago Press.

Cook, Philip J., and Jens Ludwig. 2006. The social costs of gun ownership. Journal of Public Economics 90:379-91.

Corman, Hope, and Naci Mocan. 2002. Carrots, Sticks and Broken Windows. NBER Working Paper 9061. http://www.nber.org/papers/w9061.

Eck, John E., and Edward R. Maguire. 2000. Have changes in policing reduced violent crime? An assessment of the evidence. In The Crime Drop in America, eds. Alfred Blumstein and Joel Wallman. Cambridge, UK: Cambridge University Press. 


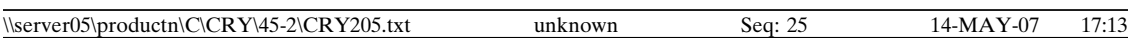

\section{POLICING, DRUGS \& THE HOMICIDE DECLINE 409}

Fagan, Jeffrey, and Garth Davies. 2003. Policing guns: Order maintenance and crime control in New York. In Guns, Crime, and Punishment in America, ed. Bernard E. Harcourt. New York: New York University Press.

Fagan, Jeffrey, Valerie West, and Jan Holland. 2003. Reciprocal effects of crime and incarceration in New York City neighborhoods. Fordham Urban Law Journal 30:1551-602.

Fagan, Jeffrey, Franklin E. Zimring, and June Kim. 1998. Declining homicide in New York City: A tale of two trends. Journal of Criminal Law and Criminology 88:1277-323.

Galea, Sandro, Jennifer Ahern, David Vlahov, Phillip O. Coffin, Crystal Fuller, Andrew C. Leon, and Kenneth J. Tardiff. 2003. Income distribution and risk of fatal drug overdose in New York City neighborhoods. Drug and Alcohol Dependence 70:139-48.

Goldstein, Herman. 1979. Improving policing: A problem-oriented approach. Journal of Crime and Delinquency 25:236-58.

Goldstein, Paul J. 1985. The drugs/violence nexus: A tripartite conceptual framework. Journal of Drug Issues 14:493-506.

Golub, Andrew Lang, and Bruce D. Johnson. 1997. Crack's Decline: Some Surprises Across U. S. Cities. National Institute of Justice Research Brief. Washington, DC: U. S. Department of Justice.

Greene, Judith A. 1999. Zero tolerance: A case study of police policies and practices in New York City. Crime \& Delinquency 45:171-87.

Harcourt, Bernard E., and Jens Ludwig. 2006. Broken windows: New evidence from New York City and a five-city social experiment. University of Chicago Law Review 73:271-320.

Infoshare Online. 2007. www.infoshare.org.

Joanes, Ana. 2000. Does the New York City Police Department deserve credit for the decline in New York City's homicide rates? A cross-city comparison of policing strategies and homicide rates. Columbia Journal of Law and Social Problems 33:265-311.

Karmen, Andrew. 2000. New York Murder Mystery: The True Story Behind the Crime Crash of the 1990s. New York: New York University Press.

Kelling, George L., and William J. Bratton. 1998. Declining crime rates: Insiders' views of the New York City story. Journal of Criminal Law and Criminology 88:1217-231. 
Kelling, George L., and Catherine M. Coles. 1996. Fixing Broken Windows: Restoring Order and Reducing Crime in Our Communities. New York: Simon and Schuster.

Kelling, George L., and William H. Sousa, Jr. 2001. Do Police Matter? An Analysis of the Impact of New York City's Police Reforms. New York: Center for Civic Innovation at the Manhattan Institute.

Kleck, Gary. 2004. Measures of gun ownership levels for macro-level crime and violence research. Journal of Research in Crime and Delinquency 41:3-36.

Land, Kenneth C., Patricia L. McCall, and Lawrence E. Cohen. 1990. Structural covariates of homicide rates: Are there any invariances across time and social space? American Journal of Sociology 95:922-63.

Levitt, Steven D. 2004. Understanding why crime fell in the 1990s: Four factors that explain the decline and six that do not. Journal of Economic Perspectives 18:163-90.

MacDonald, John M. 2002. The effectiveness of community policing in reducing urban violence. Crime and Delinquency 48:592-618.

Messner, Steven F., Glenn D. Deane, Luc Anselin, and Benjamin PearsonNelson. 2005. Locating the vanguard in rising and falling homicide rates across U. S. cities. Criminology 43:661-96.

National Research Council. 2004. Fairness and Effectiveness in Policing: The Evidence. Committee to Review Research on Police Policy and Practices, eds. Wesley Skogan and Kathleen Frydel. Committee on Law and Justice, Division of Behavioral and Social Sciences and Education. Washington, DC: The National Academies Press.

O’Brien, Robert M. 1996. Police productivity and crime rates: 1973-1992. Criminology 34:183-207.

Ousey, Graham, and Matthew R. Lee. 2002. Examining the conditional nature of the illicit drug market-homicide relationship: A partial test of the theory of contingent causation. Criminology 40:73-102.

Rosenfeld, Richard. 2002. Crime decline in context. Contexts: Understanding People in Their Social Worlds 1:25-34.

Rosenfeld, Richard, Robert Fernango, and Eric Baumer. 2005. Did Ceasefire, Compstat, and Exile reduce homicide? Criminology \& Public Policy 4:419-50. 
Sampson, Robert J., and Jacqueline Cohen. 1988. Deterrent effects of the police on crime: A replication and theoretical extension. Law \& Society Review 22:163-89.

Skogan, Wesley. 1990. Disorder and Decline: Crime and the Spiral of Decay in American Neighborhoods. Berkeley, CA: University of California Press.

Solomon, Freda F. 2003. The Impact of Quality-Of-Life Policing. New York City Criminal Justice Agency Research Brief, No. 3.

Taylor, Ralph B. 2001. Breaking Away from Broken Windows: Baltimore Neighborhoods and the Nationwide Fight Against Crime, Grime, Fear, and Decline. Boulder, CO: Westview.

Weisburd, David, and John E. Eck. 2004. What can police do to reduce crime, disorder, and fear? Annals of the American Academy of Political and Social Science 593:42-5.

Wilson, James Q., and George L. Kelling. 1982. Broken windows: The police and neighborhood safety. Atlantic Monthly 249:29-38.

Wintemute, Garen. 2000. Guns and gun violence. In The Crime Drop in America, eds. Alfred Blumstein and Joel Wallman. Cambridge, UK: Cambridge University Press.

Steven F. Messner is the Distinguished Teaching Professor of Sociology at the University at Albany, State University of New York. His research focuses on social organization and crime, the spatial patterning of crime, and crime in China.

Sandro Galea is an associate professor in the Department of Epidemiology at the University of Michigan School of Public Health. His research interests include the role of social and economic factors in shaping population health.

Kenneth J. Tardiff is a professor of psychiatry and public health in the Department of Psychiatry at theWeill School of Medicine, Cornell University. His research interests include homicide and other violence, suicide, and accidental drug overdoses.

Melissa Tracy is a research analyst in the Department of Epidemiology at the University of Michigan School of Public Health. Her research interests include determinants of mortality and morbidity in urban areas. 
Angela Bucciarelli is a research analyst with the Center for Urban Epidemiologic Studies at the New York Academy of Medicine. Areas of particular interest are spatial analytic methods and geographic information systems (GIS) technology applied to public health research.

Tinka Markham Piper is a senior project director with the Center for Urban Epidemiologic Studies at the New York Academy of Medicine. Her research interests include changing trends in fatal injury (homicide, suicide, and drug overdose) in urban areas.

Victoria Frye is a research investigator at the Center for Urban Epidemiologic Studies at The New York Academy of Medicine and an adjunct assistant professor at New York University. Dr. Frye studies the distribution and determinants of intimate partner violence against women and the roles of sociostructural and socially interactive factors in maintaining intimate partner violence at the neighborhood level.

David Vlahov is the director of the Center for Urban Epidemiologic Studies at the New York Academy of Medicine. His research interests include the epidemiology of behavior and of infectious disease transmission in urban areas. 
POLICING, DRUGS \& THE HOMICIDE DECLINE

\section{Appendix A. Univariate Statistics for New York City Police} Precincts, 1990-1999 $(N=74)^{\mathrm{a}}$

\begin{tabular}{|c|c|c|}
\hline & Mean & SD \\
\hline Homicides per $100,000^{\mathrm{b}}$ & 20.7 & 22.2 \\
\hline Gun-related homicides per $100,000^{\mathrm{b}}$ & 14.8 & 16.9 \\
\hline Non-gun-related homicides per $100,000^{\mathrm{b}}$ & 5.9 & 7.5 \\
\hline Robberies per $100,000^{\mathrm{b}}$ & 1126.0 & 977.7 \\
\hline Misdemeanor arrests per $100,000^{\mathrm{b}}$ & 4769.1 & 4981.9 \\
\hline Felony arrests per $100,000^{\mathrm{b}}$ & 2403.9 & 2120.7 \\
\hline Cocaine use $\mathrm{e}^{\mathrm{b}, \mathrm{c}}$ & 8.0 & 10.6 \\
\hline Percent male & 47.0 & 2.3 \\
\hline Percent under age 35 years & 52.1 & 7.5 \\
\hline Percent unemployed & 4.5 & 1.2 \\
\hline Firearm availability ${ }^{\mathrm{b}, \mathrm{d}}$ & 18.8 & 20.6 \\
\hline Percent black & 27.5 & 27.2 \\
\hline Percent with less than high-school education & 32.8 & 13.7 \\
\hline Percent under $200 \%$ poverty & 37.0 & 16.8 \\
\hline Percent female-headed households & 20.1 & 11.7 \\
\hline Percent receiving public assistance & 5.6 & 3.7 \\
\hline SES composite score ${ }^{\mathrm{e}}$ & 91.1 & 41.8 \\
\hline Police force in precinct ${ }^{\mathrm{b}}$ & 220.5 & 60.4 \\
\hline
\end{tabular}

ABBREVIATIONS: $\mathrm{SD}$ = standard deviation, $\mathrm{SES}$ = socioeconomic status.

a Demographic characteristics based on 1990 U.S. Census.

${ }^{b}$ Data available for each year 1990-1999.

c Proportion of accident decedents with positive cocaine toxicology.

${ }^{\mathrm{d}}$ Proportion of suicides where guns were used.

e SES composite index includes the following socioeconomic variables aggregated to the police precinct level: percent less than high-school education, percent less than 200 percent poverty, percent female-headed households, and percent receiving public assistance. 
